\title{
Repair of rigid pavement using micro concrete material
}

\author{
Jonbi Jonbi ${ }^{1,}{ }^{*}$, A. R. Indra Tjahjani ${ }^{1}$, Nuryani Tinumbia ${ }^{1}$, A. M. Pattinaja ${ }^{1}$, and Bambang $S$. \\ Haryono $^{2}$ \\ ${ }^{1}$ Civil Engineering Department, Faculty of Engineering, Pancasila University, Indonesia \\ ${ }^{2}$ Civil Engineering Department, Faculty of Engineering, Tama Jagakarsa Indonesia
}

\begin{abstract}
Rapid setting materials, especially for concrete repairs made on major arteries such as toll roads which must withstand heavy traffic. Several manufacturers of construction chemicals have been producing various types of rapid setting materials designed for use in repairing such toll roads. However, the existing toll road repair materials have not demonstrated satisfactory performance when applied in the field. This study modified micro concrete materials by adding Polycarboxylate Ether (PCE) and Polypropylene Fiber (PPF) at the time of mixing existing rapid setting materials. It then tested flow tests and setting time at 16, 20, 30, 40, and 60 minutes, as well as compressive strength; and flexural strength tests at the ageing times of 3 hours, 1 day, and 7 days. The concrete micro material was applied directly in the field. The results show that micro concrete material is definitely suitable for toll road repair. The addition of PCE and PPF can increase the flexural strength and modulus of elasticity, meaning that the material is not easily cracked under the repeated strains of heavy traffic loads. Therefore, the use of this micro concrete material has been proven to be viable for future repairs of heavily trafficked toll roads.
\end{abstract}

\section{Introduction}

In Indonesia, new toll roads are being constructed rapidly and existing arteries are increasingly being expanded. However, once toll roads are built they often undergo structural damages, such as the Cipularang toll road which connects Jakarta to Bandung. The Cipularang toll road carries heavy traffic and a high volume of vehicles. Contours of the highway that climb sharply and turn abruptly, combined with unstable base soil factors and high amounts of rainfall, result in rapid erosion and other soil issues that cause damage to the road bed and pavement surfaces, including collapsing, pumping, and spalling, as illustrated in the following photos. One of the main obstacles to performing effective repairs is the requirement that these important highways should not be closed for very long during the repair process.

* Corresponding author: nanojbg@gmail.com 

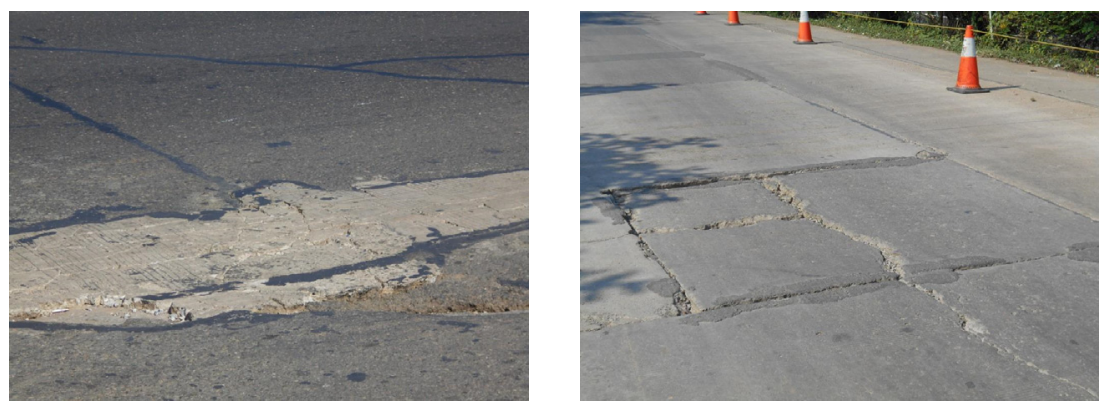

Fig. 1. Damage to the rigid pavement.

In addition, although high-early-strength cementitious repair materials are commercially available, many of these materials are especially vulnerable to cracking, poor bonding, and premature deterioration, which result from various causes such as incompatibility with the existing concrete pavement $[1,2]$.

Satisfactory repair work requires materials with rapid setting criteria that have high compressive strength and flexure strength. These important characteristics ensure longer service life. Long service life means fewer future repairs as well as longer intervals between rehabilitation and reconstruction projects, leading to significant savings in both the quantity of pavement materials required and overall expenditures [3]. Some studies have shown there have been issues arising when using high-early-strength concrete in repair applications for pavements $[4,5]$. Therefore, it is essential that good-quality local materials that have the structural capabilities to conform to, or even exceed, the standard criteria for such repairs, should be developed as quickly as possible $[6,7,8,9]$.

Polypropylene Fiber (PPF), shown in Figure 1, is a synthetic fiber with low density, fine diameter and low modulus of elasticity. It exhibits special characteristics such as high strength, high ductility, and durability. Polypropylene Fiber also demonstrates excellent bonding capabilities which can greatly improve the properties of mortar [10].

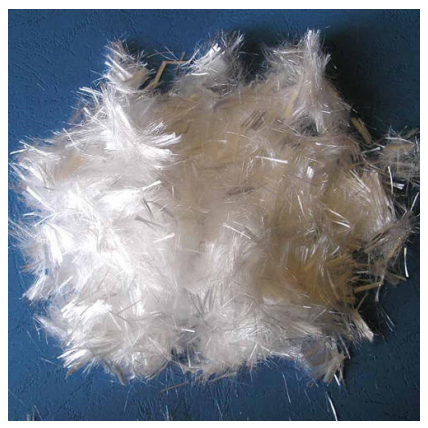

Fig. 2. Polypropylene Fiber.

This research developed micro concrete material in accordance with the criteria needed for effective repair work in the rigid pavement. This development was accomplished by adding superplasticizer and Polypropylene Fiber (PPF) to existing commercially available repair materials.

\section{Materials and methods}

Two types of materials were utilized in this research: Estopatch RSP and Patchroc RSP. Estopatch RSP is supplied by Estop Indonesia Corporation, and Patchroc RSP is supplied 
by Fosroc Indonesia Corporation [11]. Both types of materials are fast-setting micro concrete, and are readily available commercial products. The fiber used, Polypropylene Fiber (PPF) supplied by Sika Indonesia Corporation, has the following properties: fiber length $12 \mathrm{~mm}$; diameter 18 microns; tensile strength 300-400 MPa; elastic modulus 6000$9000 \mathrm{~N} / \mathrm{mm} 2$; specific gravity $0.91 \mathrm{~g} / \mathrm{cm} 3$. The superplasticizer used is Polycarboxylate Ether (PCE), supplied by John Hi-Tech Contrindo Corporation.

The mix proportions of each specimen are shown in Table 1. Specimen A0 is Estopatch RSP material; A1 is A0 plus 50 grams PPF $(0.2 \% \times \mathrm{A} 0)$, and A2 is A0 plus 50 grams PPF $(0.2 \% \mathrm{xA} 0)$ and 0.25 litres superplasticizer PCE (1\% x A0). Specimen B0 is Patchroc RSP; $\mathrm{B} 1$ is $\mathrm{B} 0$ plus 50 grams PPF $(0.2 \% \times \mathrm{B} 0)$ and $\mathrm{B} 2$ is $\mathrm{B} 0$ plus 50 grams PPF $(0.2 \% \times \mathrm{B} 0)$ and 0.25 litres superplasticizer PCE (1\% x B0).

Table 1. Mix proportions of specimen.

\begin{tabular}{|c|c|c|c|c|c|c|}
\hline \multirow{2}{*}{$\begin{array}{c}\text { Mix } \\
\text { Proportions }\end{array}$} & \multicolumn{7}{|c|}{ Specimen } \\
\cline { 2 - 7 } & A0 & A1 & A2 & B0 & B1 & B2 \\
\hline Binder (kg) & 25 & 25 & 25 & 25 & 25 & 25 \\
\hline Water/binder & 0.15 & 0.15 & 0.15 & 0.15 & 0.15 & 0.15 \\
\hline PPF (gram) & - & 50 & 50 & - & 50 & 50 \\
\hline PCE (litre) & - & - & 0.25 & - & - & 0.25 \\
\hline
\end{tabular}

A compressive strength test of $50 \times 50 \times 50 \mathrm{~mm}$ cubes in accordance with ASTM C39 for concrete ages of 3 hours, 1 day and 7 days was recorded. Flexural testing of $50 \times 50 \mathrm{x}$ $30 \mathrm{~mm}$ prisms or beams in accordance with ASTM C78 / C78M-18 [12] were measured at ages of 3 hours and 1 day, while the initial setting time was recorded based on ASTM C403 / C 403-99 [13].
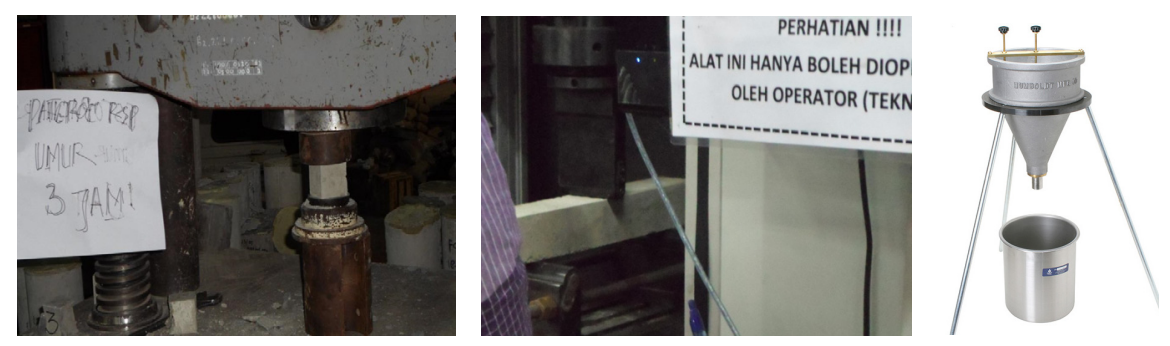

Fig. 2. Test equipment for specimens.

\section{Results and discussion}

\subsection{Setting time}

The result of the time setting test is shown in Figure 3. Material B0 sets faster compared to material A0. These results indicate that both materials are rapid setting, because they can harden in less than 60 minutes. Setting time is an important factor for cost-effective rigid pavement repairs, because reducing total work time (and highway usage down time) is critical when major highways are involved. Setting time also indicates when, and how 
easily, a particular type of material can be applied. Significantly, including PPF in the concrete mixture does not have obvious negative effects on the setting times for either material, $\mathrm{A} 0$ and $\mathrm{B} 0$.

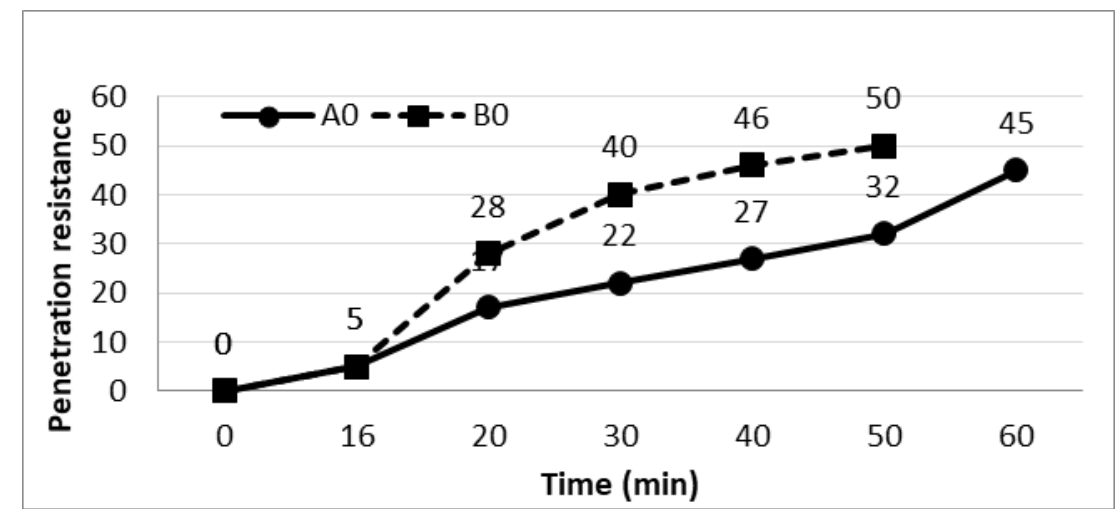

Fig. 3. Result of setting time test.

\subsection{Compressive strength}

The results of the compressive strength tests are shown in Figure 4. Significant improvements occurred with the addition of PPF as well as the addition of PPF and Admixture. At the age of 3 hours for A0: $22.2 \mathrm{MPa}, \mathrm{A} 1: 23.1 \mathrm{MPa}$ there is an increase of $4 \%$, while for A2 of $24.3 \mathrm{MPa}$ there is a $9.5 \%$ increase. For B1 specimens at $3 \mathrm{~h}$, there was an increase of B0: $21.9 \mathrm{MPa}$ to $22.9 \mathrm{MPa}, 4.5 \%$ increase; B2 increased by $15 \%$ to 25.2 $\mathrm{MPa}$. At the age of 1 day, on specimens A1 and A2 compressive strength increased by $2.9 \%$ and $24.3 \%$ respectively. As for B1 and B2, compression strength increased by $13.5 \%$ and $35.5 \%$. 7-day age specimens exhibited an increase in compressive strength for A1 of $0.9 \%$; A2 of $11.2 \%$; B2 of $1.4 \%$; and B2 of $9.9 \%$. Based on the results of the compressive strength test, the addition of PPF and admixture can increase the compressive strength by $11.2 \%$ and $9.9 \%$. This result is in line with previous research that states that adding polypropylene fibers to mortar can increase compressive strength and reduce plastic shrinkage cracks [14].

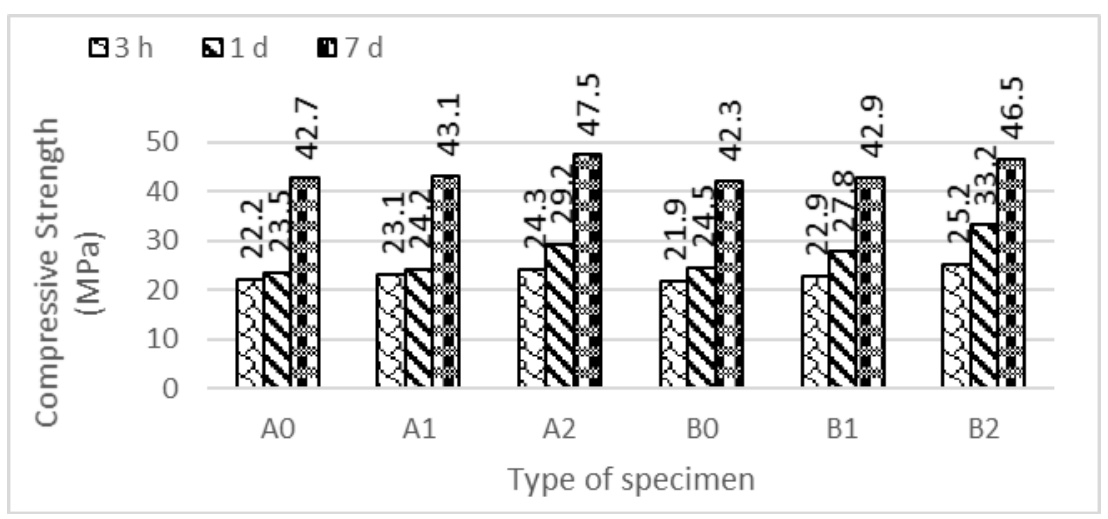

Fig. 4. Result of testing the compressive strength.

This enhancement may stem from improvements in the mechanical bond strength as the introduction of the ductile, durable fibers enable the concrete material to delay 
micro-crack formation and even arrest their propagation afterwards to a certain extent [15]. Additionally, empirical evidence shows that the addition of superplasticizer can improve the workability of HPC due to the presence of PCE nanoparticles in the concrete slurry, which can fill any cavities within the concrete and thus result in strengthening of the bonds between the components of the mixture. [16].

Moreover, the use of fibers in the mortar or concrete can significantly enhance the bond strength between the old substrate and the new repair materials, which is one of the most important requirements for a successful repair [17].

\subsection{Flexural strength}

The flexural strength test results are shown in Figure 5. At an age of 3 hours, flexural strength in sample A0 is $3.1 \mathrm{MPa}$, which increased by $9.7 \%$ to $3.4 \mathrm{MPa}$ in specimen A1. A2 increased by $22.6 \%$ to $3.8 \mathrm{MPa}$. Although for specimen $\mathrm{B} 1$ there is an increase of $12.5 \mathrm{MPa}$ (B0: $3.2 \mathrm{MPa}, \mathrm{B} 1: 3.6 \mathrm{MPa}$ ), for $\mathrm{B} 2$ there is an even larger increase of $25 \%$ to $4 \mathrm{MPa}$. At the age of 1 day, an increase of $58.3 \%$ was recorded. A0: $3.6 \mathrm{MPa}$; A1: $5.7 \mathrm{MPa}$; A2: 6.9 $\mathrm{MPa}$ (an increase of 91.7\%). Specimen A0 at 7 days was 7.1 MPa; A1: $8.7 \mathrm{MPa}(22.5 \%)$ and A2: $10.3 \mathrm{MPa}$ (an increase of 18.4\%). Then at 7 days, specimen B0 was recorded at 7.2 MPa; B1: 8.6 MPa (19.4\%); B2: $10.4 \mathrm{MPa}(44.4 \%)$.

The flexural test results show the addition of PPF and the effective admixture can improve the flexural strength in materials A0 and B0. This shows both A0 and B0 materials can be used as repair materials for rigid pavement roads, and the quality of the repairs would improve even more if combined with PPF and admixture.

As a further benefit, adding polypropylene fibers to the cement composites is also an effective method of preventing crack formation [18]. The short polypropylene fibers, when distributed uniformly throughout the entire volume of concrete, act to sew the edges of cracks together and restrict any further propagation [19]. Obviously, reduction of cracking is of great importance, especially in the first hours after pouring before the concrete reaches its full strength [20].

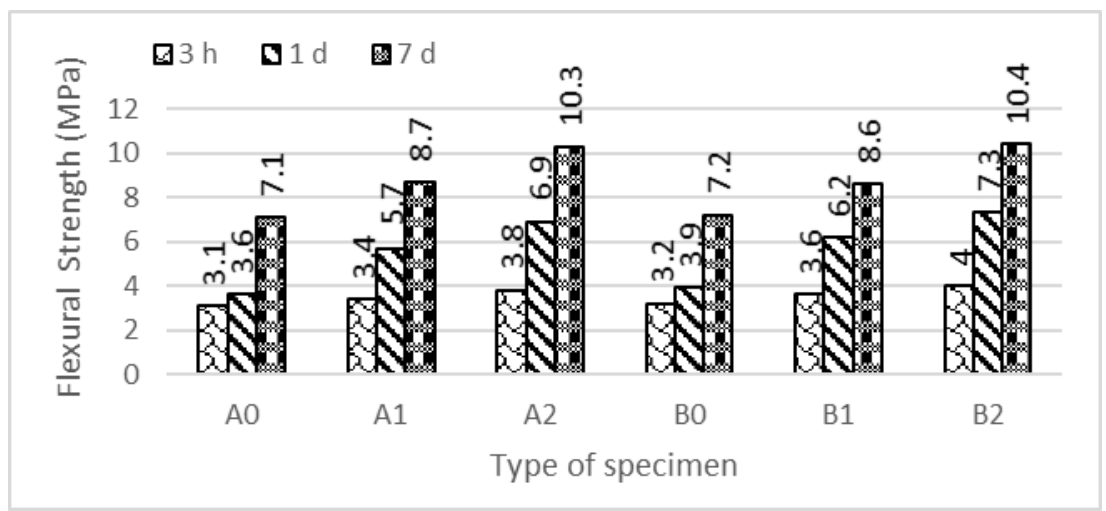

Fig. 5. Result of testing the flexural strength.

\section{Conclusions}

1. The use of either Polypropylene Fiber (PPF) or Polypropylene (PCE) is highly effective to improve the compressive strength and flexural strength of concrete mixtures used in repairing heavily trafficked road surfaces such as toll roads. 
2. Adding PPF and PCE significantly improves the compressive strength by $11.2 \%$ and the flexural strength by $18.4 \%$ for material $\mathrm{A} 0$, and increases the compressive strength by $18.4 \%$ and flexural strength by $44.4 \%$ for material B0

The author thanks the financial support from Ministry of Research Technology and Higher Education of the Republic of Indonesia for this Research Grant with the Scheme of Penelitian Berbasis Kompetensi for the year 2018.

\section{References}

1. Li, M, Victor, C. L. ACI Mater. J, 108, pp. 3-12 (2011)

2. H. Soliman, A. Shalaby, Constr. Build. Mater, 70, pp. 148-157 (2014)

3. K. Hall, Federal Highway Administration, Washington, DC (2007)

4. C. Huang, S. Lin, C. Chang, H.C. Chen, Constr. Build. Mater. 46, pp. 71-78. (2013)

5. D.P. Bentz, M.A. Peltz, ACI Mater. J. 105. pp. 414-420 (2008)

6. J. Jonbi, B. Hariandja, I. Imran, I. Pane, AMM, 175-177, pp. 1067-107 (2012)

7. J. Jonbi, B. Hariandja, I. Imran, I. Pane, 450-451, pp. 277-280 (2012)

8. A.R.I. Tjahjani, J. Jonbi, R. Riadika, R. Mulyani, AMR 991-921.pp 1836-1838. (2014)

9. H. Simatupang, AIP Conf. Proc. 1887, 020028-1-020028-8 (2017)

10. S. Singh, A. Shukla, R. Brown, Cem.Concr. Res., 34, pp. 1919-1925, (2004)

11. Technical Book of Estopatch RSP ex PT. Estop; Patchroc RSP ex PT. Fosroc; PPF ex PT.Sika

12. American Society for Testing and Materials (ASTM). (2015)

13. American Society for Testing and Materials (ASTM). (1999)

14. Song, P-S., and C-J, Tu., Journal of C.C.I.T., 43 (2014)

15. E. T. Dawood \& M. Ramli, Build Mater. 24 1043-1050 (2010)

16. Tan Rong Zhabf, Xiang Min Kong, Zhen Bao Lu, Zi Chen Lu, Shan Shan Hou, Cem Concr Res 67 (184-196) (2015)

17. C. Zanotti, N. Banthia, and G. Plizzari, Cem.Concr.Res, 63, pp. 117-126 (2014)

18. Khaliq, W., and Kodur, V., Cem. Concr. Res.41, pp. 1112-1122 (2014)

19. Alz T, Sanjazan JG, Collins F, Mater, and Struct 41: 1741-1753 (2008)

20. Barluenga G, Cem. Concr. Res 40: 802-809. 8 (2010) 